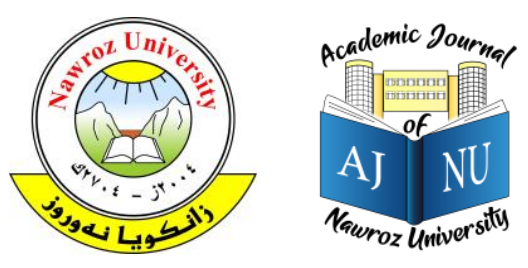

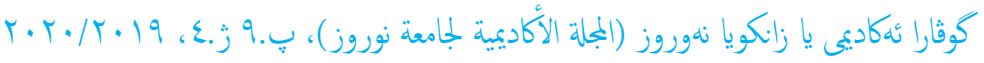

حقوق الطبع والنشر (2017. هذه مقالة الوصول اليها مفتوح موزعة تحت رخصة

e-ISSN: 2520-789X ،CC BY-NC-ND 4. 0. - المشاع الايداعي النسبي

https://doi.org/10.25007/ajnu.v9n4a915

\title{
اثر استخدام استراتيجية الحزائط الدلالية في تنمية الانتباه و التحصيل المعرفي لبعض مفردات مادة طرائق التدريس
}

د محمد مدي ممد امبارك، قسم التزبية الرياضية، فاكلتي التزبية، جامعة زاخو، كردستان العراق

هدف البحث الكشف عن اثر استخدام الخرائط الدلالية على تنمية الانتباه و التحصيل المعرفي لمادة طرائق التدريس. تمثل مجتع البحث من طلاب السنة الدراسية الثانية في قسم التربية الرياضية / فاكولتي

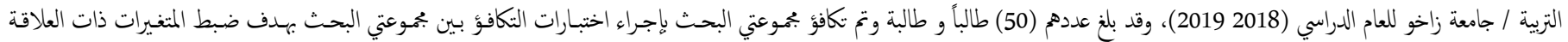

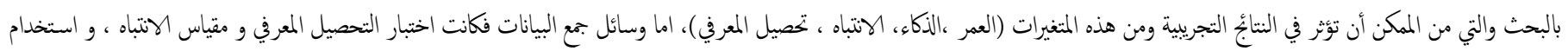

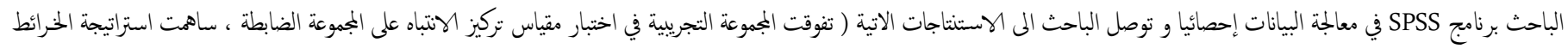

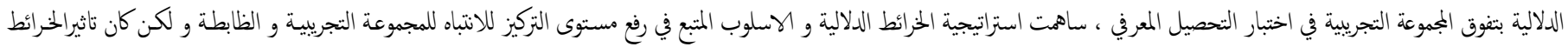

الدلالية اكبر من الاسلوب المتبع )

الكلمات المثتاحية : ( استراتيجية الخزائط الدلالية، الانتباه، التحصيل المعرفي)

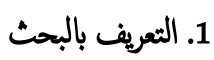

العقلية في إدراك تلك الروابط و تنظيهها وان التعليم يكون فعالاً إذا ما حسه الطالب 1.1

بأنه ذو معنى وأن التعليم ذو معنى يعد الاساس في تعديل السلوك على خلاف التعليم التقليدي الذي لا يسهم في تعديل السلوك ، ان استراتيجيات ما وراء المعرفة تعني قدرة الطالب على التخطيط و الوعي بالخطوات و الاستراتيجية التي يتخذها لحل المشكلات وكذلك على اهتمامه بمعرفنه كف يفكر ويتعلم لأن ما وراء المعرفة هي المعرفة بكيفية عمل العمليات المعرفية والوعي بالفهم، ان استراتيجية الخرائط الدلالية تعد احدى استراتيجيات ما وراء المعرفة لاقت اهتما كبيراً في الونة الاخير من قبل

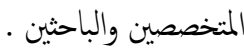
تعد الخرائط الدلالية عبارة عن رموز لفظية ميزة تدل على الافكار مجردة عامة حول فئة من الموضوعات ذات السمات المشتركة وتوجد فيا بينها ارتباطات لايمكن إدراكها مباثرة إلا عن طريق الثفكير المنطقي الذي يفر هذه الارتباطات والثفاعلات بنها" (قرني، 2013، إذ ان تركيز الانتباه للعملية التعليمية و تنميها لدى الطالب من الاهداف الاساسية والمرجوة في التدريس في جميع مراحل التعليم المختلفة كما وانها تفيد في فهم هيكله العام لهذا فإن تركيز الانتباه و تنميته لدى الطلبة يتطلب استراتيجية تدريسياً مناسباً
أهم ميزه في عصرنا الحالي هو التطور السريع والهائل في جميع مجالات الحياة وخاصة في المجال المعرفي، فهذا التطور يتطلب منا مواكبة هذه النغيرات السريعة في جميع العلوم وخاصة مجال الندريس ومنها المناجج وطرائق تدريسها من أجل مواكبة التغيرات السريعة في موابجة تحديات هذا العصر، لنا فإن عملية التجديد والتحديث في مجال طرائق التدريس لم تعد مجال نقاش بل اصبحت نقطة انشغال الباحثين والمتخصصين ومطلباً ملحاً من أجل إحداث التوازن بين الحياة سريعة في عصر المعرفة. تعتبر مادة طرائق التدريس من المواد الاساسية التي تدرس في كليات واقسام التربية الرياضية التي تختلف في طبيعتها عن المواد الدراسية الاخرى والتي تعتد بشكل كير في اشراك الطلبة في النشاطات العلمية والعملية المختلفة حيث يقومون بمارسة بمحوعة من النشاطات العلمية مما يجعل المدرس يستخدم استراتيجيات متنوعة وحديثة فدرس مادة طرائق التدريس يجب ان يزكز على تحبيب وتزغيب الطلبة في تثقيف الذات من خلال الاستراتيجية المستخدمة.

أن استراتيجيات الندريس القائمة على البناء المعرفي تستند المى النظريات المعرفية التي تشدد على الروابط الموجودة بين ما يتعلمه الطالب و أفكاره و خبراته السابقة ومهارته 


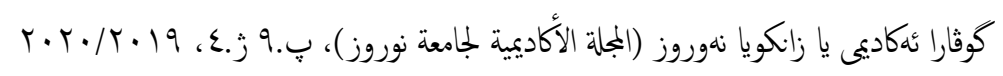

استراتيجية تعمل على تنمية تزكيز الانتباه و تزيد من اكتسابهم للتحصيل المعرفي لهذا ارتى الباحث بأن هنالك حاجة ماسة لاستخدام استراتيجية حديثة يكن أن تعمل على اكتساب التحصيل المعرفي و تنمية تركيز الانتباه لدى الطلبة مثل استراتيجية الخرائط الدلالية. وتحدد مشكلة البحث الحالي بالتسائل التالي ما اثز استخدام استراتيجية الخرائط الدلالية على تنمية الانتباه و التحصيل المعرفي لبعض مفردات مادة طرائق التدريس لدى طلبة قسم التربية الرياضية / فاكولتي التربية / جامعة

$$
\text { زاخو. } 3.1 \text { أهداف البحث }
$$

- أثر استخدام الخرائط الدلالية في تركيز الانتباه لمادة طرائق التدريس على طلبة المرحلة الثانية في قسم التربية الرياضية فاكولتي التربية جامعة زاخو. - - اثر استخدام الخرائط الدلالية في التحصيل المعرفي لمادة طرائق الندريس على طلبة المرحلة الثانية في قسم التربية الرياضية فاكوتي التربية جامعة زاخو.

\section{1 فرضيتا البحث}

- - وجود فروق ذات دلالة إحصائية بين متوسط درجات طلاب الجمموعة التجريبية التي تدرس وفق استراتيجية الخرائط الدلالية وبين طلاب الجمموعة الضابطة والتي تدرس وفق الأسلوب المستخدم في تركيز الانتباه ولصاح المجموعة التجريبية. - - وجود فروق ذات دلالة إحصائية بين متوسطة درجات طلاب الجمموعة التجريبة التي تدرس وفق استراتيجية الخرائط الدلالية وبين طلاب الجمموعة الضابطة والتي تدرس وفق الاسلوب المستخدم في اختبار التحصيل المعرفي لمادة طرائق الندريس ولصاح الجمموعة التجريبة.

5.1 بجالات البحث

- - المجال البشري: طلبة المرحلة الثانية / قسم التربية الرياضية/ فاكوتي التربية/ جامعة زاخو.

- - المجال الزماني: الفصل الدراسي الثاني للعام الدراسي 2018- 2019 للفترة من $2019 / 3 / 7$ 2019/28
تضمن سلامة الانتباه للمحاضرة، وكذلك التحصيل المعرفي بمفومه الحديث إكتساب المعارف العلمية التي يكن من خلالها الوصول الى الاهداف الدراسية بطرقة علمية منتظمة من أهم الاهداف التي يسعى المدرس الي تحتيقها حيث ان التحصيل المعرفي يمثل أحد مستويات البناء المعرفي للمادة التعلمية التي تبنى عليها مكونات باقي المعرفة ويعتبر التحصيل المعرفي أحد نواتج العلم التي يكن من خلالها تظيم المعرفة العلمية . مما تقدم تكمن أهمية البحث الحلالي فيا يأتي:يستمد البحث أهميته من خلال تصميم برنامج تعليمي خاص باستخدام استراتيجية الخرائط الدلالية من خلال اجراءاته التي تتمشى مع عصر المعرفة و دروها في رفع تركيز الانتباه و مستوى التحصيل المعرفي لمادة طرائق التدريس لدى الطلبة من خلال تفاعل الطلبة لهذه الاستراتيجية و مساهتها في حدوث تعلم أفضل وصولاً المى تفاعل و تعليم نشط و فعال يؤدي المى نتائج ومخرجات هادفة تنشد الهيا جميع الكليات في الجامعات لخلق جيل متعلم منتج. تويل التعليم الصفي من عملية التلقين الى تدريب الطلبة على اكتساب محارات تعلمية تمكنه من الاستفادة مما تعلموه وتساعد على تخريرهم من الناذج الثابتة من التفكير المعتمد على الرد وحشو الاذهان، وهذا لا يكون سهلاً إلا إذاكن هناك دوافع نخو التعليم والبحث عن الجديد لدى الطلاب الم من خلال استخدام استراتيجيات ماوراء المعرفة و منها استراتيجية الخرائط الدلالية. اهمية هذه الدراسة في خلق ابداعات وابتكرات من خلال تحفيز التفكير الابنكاري لدى الطلبة لطبيعة مادة طرائق التدريس وخصوصيتها في ايجاد ابتكارات جديدة في مفرداتها وذلك من خلال التفاعل بين المادة التعلمية والطالب وتوضيفها لصالح الابتكار والابداع لمادة طرائق التدريس.

2.1

لقد شعر الباحث بأهمية تنمية تركيزالانتباه و التحصيل المعرفي لمادة طرائق التدريس من خلال عمله كندريسي في قسم التربية الرياضية و مدرساً لمادة طرائق التدريس حيث لاحظ أن بعض الطلبة يوابهون بعض الصعوبات في اكتساب التحصيل المعرفي و تشتت انتباههم اثناء المحاضرة وان الاستراتيجيات المستخدمة للندريس لم تعمل على اكتساب المفاهيم بصورة سليمة وتشتت انتباه لدى الطلبة ومن خلال مراجعة الباحث الى الاستراتيجيات التدريس الحديثة توصل الى ضرورة استخدام 


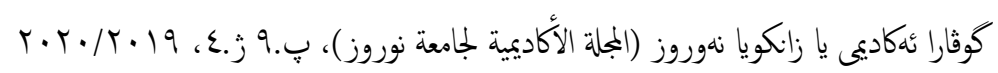

تعتمد استراتيجية خرائط الدلالية على فكرة تمثيل الخارجي للمعرفة في اشكال او خرائط تبرز العلاقات المختلفة بين المفاهيم او الفكار اوبين عناصر المادة القروءة فتعمد استراتيجية خريطة الدلالية على خرائط المعرفة باشكالها المتنوعة

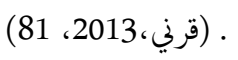

سلسلة من الاجراءات التي يتم فهيا عرض و تدريس المادة العلمية عن طريق بناء خخطط يمثل مجموعة من الافكار او العناوين المتضمنة لموضوع ما حيث يتم ترتيها بطريقة قد تكون ثنائية البعد او دائرية او خطوات متتالية او في اثكلال

مقارنة او خرائط متشعبة. ( نوفل و سفيان، 2011، 228)

2.1.2 نظريات الخرائط الدلالية

1.2.1.2 نظرية دلالات الولفاظ

تستند هذه النظرية المى افتراضيات في مفردات اللغة و معانيها لا تتكون من قائمة عشوائية من الكلمات و المفاهيم بل ترتبط بالكثير من القوائم الكلمات و المفاهيم التي ترتبط بدورها مع بعضها البعض بعلاقات مقعدة و متشابكة ، و القوائم تكون مقسمة على مجالات عامة ويتكون كل مجال من بعض الفروع ويتكون كل فرع من مجموعة من الكلمات و المفاهيم المتتشابهة و المتناعمة في معانيها، يرتبط كل مجال بالمجال الاخر بعلاقات توضع في شكل نسيج او شبكات تشبه الشبكات الموجودة في عقل الانسان، وهذا يرتبط باستثارة عقل الانسان بمعلومات ترتبط بمجال ما فانه يستدعي كل ما يرتبط بهذا المجال من مفردات و معان، فمثلاً عند استثارة عقل الطالب بمعلومات حول خطة الدرس فانه يستدعي كلمات و مفردات مثل اجزاء الدرس واهداف الدرس و زمن الدرس و ماهي الفعالية التي سوف تدرس و كيف ....الخ من افكلر مرتبطة بخطة الدرس وجميع هذه المفردات مترابطة مع بعضها البعض.

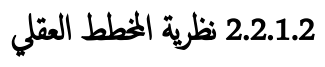

تستند هذه النظرية على ان عقل الانسان مكون من ابنية افتراضية فيها ماهو معروف وما يتعلم من معلومات وهذه الابنية تكون شبكات من المعرفة وكل شبكة تمثل مجالاً معيناً من مجالات المعرفة وتسمى مخططات او شبكات او اطر داخلية، وعندما يستثار عقل الانسان بمعلومات جديدة يتعرف عليها اولا ثم يقوم بتفسيرها في ضوء خبراته السابقة و الخختبرية في هذه الاطر و الشبكت التي تقوم بدورها بتخزين المعلومات المكتسبة لاستعالها في فهم معومات و معارف جديدة.
- - المجال المكاني: القاعة الرياضية في قسم التزبية الرياضية / فاكولتي التزبية /جامعة زاخو.

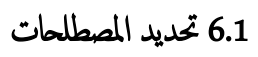

- - - استراتيجية خرائط الدلالية: - استراتيجية تدريس يشترك فيها المدرس والطالب

لتصنيف نص أو جموعة من النصوص الدراسية على شكل مخططات متنوعة

تفصل فيها المعلومات والمفاهيم على نخو مدروس ومنظم (المسعودي، 2013،

99). ويعرفها الباحث اجرائياً: استراتيجية تدريس يتبعها المدرس مع الطلبة

تستند الى تصنيف وترتيب النص على شكل خرائط متنوعة حسب نوع

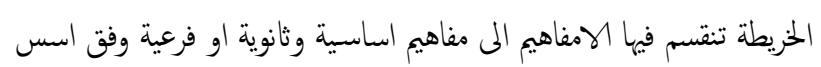

بناء الخزيطة بجيث تساعد الطالب على تركيز الانتباه ورفع من مستوى

التحصيل المعرفي لمادة طرائق التدريس.

- - الانتباه: مدى ارتباط الطالب بالمحاضرة والمدرس والابتعاد عن الشرود الذهني والملل التي تسهل عليه فهم واستيعاب وهظم المادة النعلمية بصورة سليمة

وصحيحة.

- - التحصيل المعرفي: مقدار الدرجة التي يحصل عليها الطالب في مادة طرائق الندريس في الاختبار المعد لهذا الغرض.

2. الاطار النظري و الدراسات السابقة

1.2

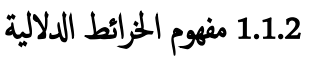

الخرايط الدلالية هي وسيلة لتنظيم المحتوى التعليمي و تعلمه وتكون عبارة عن مجسات تمثل الافكار الرئيسة وهذه الافكار تأتي على شكل مقدمة و عرض و خاتمة غالباً ما ثأتي الافكار الرئيسة في وسط الشكل او الخريطة ثخ تخيط به الافكار الثانوية حيث تعد من الاستراتيجيات التربوية الفعالة لتنظيم المحتوى و الافكار وتسهيل فهم الطالب للمعلومات المكتسبة حديثاً اذ ان استخدامحا يساعد الطلبة على فهم ما تم تعلمه وتمثل وسيلة بصرية جيدة للمدرس و للطالب يستطبع كل منها عن طريقها ان يرى كيف يفكر في مضمون المحتوى التعليمي. (الزهيري، 2018، 32) هنالك تعريفات متعددة لخرائط المفاهيم نذكمنها: 


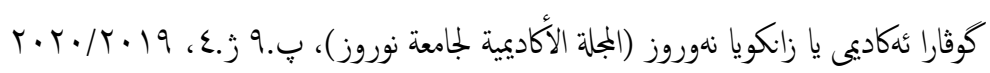

الاندماج في الدرس مع بموعة صغيرة من الطلاب.

$$
\text { تلخيص المعلومات مع زميل اخر له. }
$$

تعطي ملاحظات لخطبة او حديث مرتجل .

تكون كثثيقة عرض اولية لتقرير بثثي موسع.

كتابة مقال ذات صيغة اقناعية او كنابة تقرير حول معلومات ما.

(المسعودي،2013، 98)

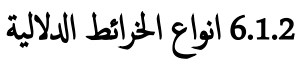

خريطة التنظيم التتابعي للقصة: القصة سلسلة من الحلقات تبنى في ضوء قواعد معينة إلى الترتيب الزمني المنطقي والخريطة الدلالية تستخدم هنا لإعادة ترميز و تنظيم القصة حسب أحداثها وترتيها وتتابعاتها الزمني، وترسم الخزيطة في شكل عقد (مربعات، مثلثات، .....) يكتب فيها نقاط أساسية في القصة ثخ يربط بينها أسهم و خطوط تبين العلاقات التي تربط بين أحداث وعناصر وأفكار القصة. ويلاحظ الطلاب في هذه الخريطة كيفية تحول القصة الأساسية

$$
\text { الى عمل قصص قصيرة وتسلسها. }
$$

الخريطة الوصفية: تستخدم هذه الخزيطة مع الموضوعات التي تضم تفاصيل الأماكن و الشخصيات و الأشياء العامة، والخريطة الوصفية تعرض المكونات والثفاصيل والأماكن التي تدور حول فكرة رئيسة و ترسم هذه الخريطة بوضع الفكرة الرئسية في مركز الخزيطة ثم يتفرع عنها أفكار فرعية ثم التفاصيل الداعة، ثم تبين العلاقات بين الفكرة الرئيسة و الافكر الفرعية والثفاصيل عن طريق رسم خطوط وأسهم توضح نلك العلاقات. كما يتم استخدام بعض الأشكال الهندسية مثل: المربع للفكرة الرئيسة و الدوائر للأفكار الفرعية ثخ المثلثات او المعينات للتفاصيل وهكذا كلما زادت الفروع زادت معها الأشكال . خريطة التباين والمقارنة: تستخدم هذه الخريطة مع الموضوعات التي تختوي على معلومات متناقضة وهذه الخزيطة توضح نواحي الاتفاق ونواحي الاختلاف المتضمنة في موضوع الدرس، ترسم هذه الخريطة بموضوع الرئيسي في مقدمة الخريطة أو وسطها ثم توضح في أحدى جانبي الخزيطة نواحي الاتفاق ويربط بينها خطوط وأسهم مستقيمة تدل على اتفاق المعلومات .
ان الخزائط الدلالية هي تطبيق لنظريتي الالفاض الدلالية و الخخطط العقلي حيث يثر المدرس المعلومات السابقة المختزنة في الخطط العقلي للطلاب ثخ يضع مع الطلاب هذه المعلومات في تصنيفات متشاهة، ويربط مع بعضها في شكل خريطة دلالية للموضوع ويعيد ترتبه و تنظمه في مجالات متشابه في خريطة دلالية للموضوع وهذا يساعد الطالب على ربط المعلومات الجديدة في النص بالمعلومات السابقة واكتساب معومات اخرى جديدة. (المسعودي،2013، 110-111) 3.1.2 أهية استخدام الحرائط الدلالية في الثدريس أن العقل البشري مقسم الى نصفين النصف الايسر و يختص بالمعومات اللفضية و اللغة و عمليات التفكير المنطقي اما النصف الايمن فيختص بالعلاقات المكانية و الصور المرئية و هو مركز الابداع و التخيل، فإذا عرض على العقل معلومات لفظية قام النصف الأيسر بعمله دون النصف الايمن وإذا عرض على الطالب صور و أشكال مرئية قام النصف الايمن بعمله دون النصف الايسر ، ومن اجل ان يعمل العقل كوحدة متكملة يجب ان يتناغ النصف الايمن مع النصف الايسر، وذلك من خلال بناء خرائط دلالية للموضوعات تحتوي على الصور و رسوم بيانية بالاضافة المى الفاظ و تراكيب لغوية. ( قرني، 2013، 83)

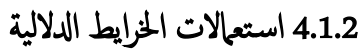

تستعمل الخزائط الدلالية لتنمية المفردات: اذ يشجع المدرس الطالب من خلالها على الثفكير في بعض الكلمات المتزابطة في الموضوع و ربطها بالفكرة الرئيسية وعلى ضوء ذلك استعالها لتنمية مفردات لدى الطالب و مساعدتهم على التعرف على العلاقات بين المفردات و كيفية تصنيفها. تستعمل الخزائط لتنمية همارات الاستذكار ويتم ذلك عندما تستعمل الخزيطة الدلالية بصيغة يتمكن الطالب من خلالها قراءة الموضوع قراءة متأنية لاستخراج تفاصيل يكن اضافتها للخريطة الدلالية للوصول بها المى افضل شكل . تستعمل الخرائط الدلالية في تدريس القراءة من خلال عرض كلمات مرتبطة بموضوع قرائي معين و يستثير المدرس خلفية الطلبة المعرفية بتوجيه اسئلة مترابطة بالموضوع الرئيسي و عليه يدفعهم المى مناقشة و تصنيف المعلومات و ري الافكار المترابطة بالموضوع .(الزهيري، 2018 ،48

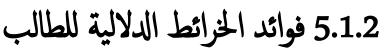




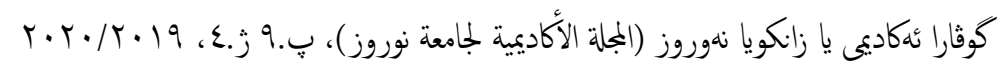

هدفت الدراسة المى التعرف الى معرف اثر الخزائط الدلالية في التحصيل و الاستبقاء لدى تلميذات الصف الخامس الابتدائي في مادة العلوم العامة، و استخدم الباحثون المنهج التجريبي لملائته لاهداف البحث ، طبق البحث على تلميذات الصف الخامس الابتدائي في مدرسة غرناطة الابتدائية للبنات للعام الدراسي 2011-2010 ، وكانت اداة جمع البيانات اختبار التحصيل المعد من قبل الباحثون ، واستخدموا الوسائل الاحصائية التالية (اختبار التائي للعينات المستقلة و المتزابطة،اختبار مربع كاي ، معامل ارتباط بيرسون، معامل الصعوبة و قوة التميز بين الفقرات، و فاعلية البدائل الخطأ لفقرات الاختبار) و استنتج الباحثون ( ان استخدام الخزائط الدلالية في تدريس مادة العلوم للصف الخامس الابندائي أدى الى الحصول على نتائج ايجابية في النحصيل و اختصاراً لزمن تعلمها مقارنة بالطريقة الاعتيادية ، للخرائط الدلالية أثز فعال في استبقاء التحصيل ) .

\section{3. إجراءات البحث} 1.3 منهج البحث

المنهج الذي أستخدم هو المنهج التجريبي لملاءمته مع طبيعة مشكلة البحث.

2.3 مجتمع البحث وعينته تمثل مجتع البحث من طلاب السنة الدراسية الثانية في قسم التربية الرياضية فاكوتي التربية / جامعة زاخو للعام الدراسي (2018-2019) وقد بلغ عددهم (50) طاباً و طالبة موزعبن على شعبتين (أ،ب) . وبعدها اختيرت إحدى الشعبتين عن طريق القرعة لتمثل الجمموعة النجريبية فكانت الشعبة (أ) والتي تدرس وفق استراتيجية الخرائط الدلالية بينا مثلت الشعبة الاخرى (ب) المجموعة الضابطة و التي تدرس وفق الاسلوب المتبع ، استبعد الباحث عشرون طالباً و طالبة، والطلبة المستبعدين هم من الراسبين و الذين استخدموا للتجارب الاستطلاعية و ثبات مقياس تركيز الانتباه والذين لديهم غيابات منكررة وعليه أصبحت عينة البحث مكونة من (30) طالباً كما مبين في الجدول (1) مبرين 1 الجدول 1

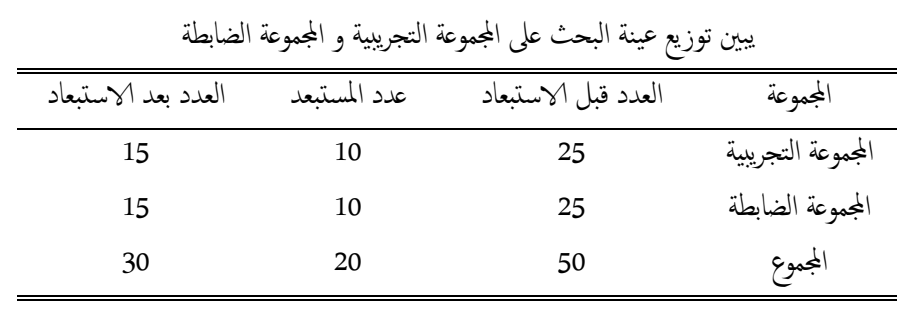

خريطة التصنيف: يستخدم هذا النوع من الخزائط مع الموضوعات التي تشتمل على مفاهيم وتصنيفات وخصائص تدور حول موضوعات متنوعة. وفي هذا النوع من الخرائط يتم ربط بين كل صنف وخصائصه وصفاته المميزة له ، وذلك عن طريق وضع المفوم الرئسي في قمة الخريطة تم يوضح تحته الأمثلة والأخبار والخصوصيات ..... مع ربط جزء بالاخر بخطوط تدل على العلاقة بنها. ومن خلال ما سبق يتضح أن الخزيطة الدلالية تتعدد أشكالها حسب نوع المادة المقروءة والهدف من الدرس لكن الأجراء العام يتع في كل الخرائط أن توضح الأفكرا الرئيسة في ارتباط مع الأفكار الفرعية والتفاصيل التي تدعمها على أن يوضح كل عنصر من هذه العناصر في شكل هندسي مثل المربعات والمثاثات والمعينات ويربط بنيها خطوط مستقمة أو متعرجة أو أسهم. (قرني، 2013، 48-89)

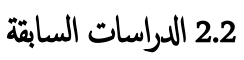

1.2.2 دراسة: عبدالسلام (2018) اثر استراتيجية الحرائط الدلالية وفقًا للسيادة المخية في التفكير ما وراء المعرفة و تعلم مهارتي الضرب الساحق و حائط الصد بالكرة الطائرة هدفت الدراسة الى التعرف على (نوع السيادة الخخية لدى مجموعات البحث، التفكير ما وراء المعرفي لدى جموعات البحث ، اعداد خريطة دلالية وفقاً لنوع السيادة الخخية)، واستخدمت الباحثة المنهج التجريبي للمجموعتين الظابطة و التجريبية ذات الاختبارين التبلي و البعدي لملأمتنه لأهداف و طبيعة البحث ، و اجري البحث

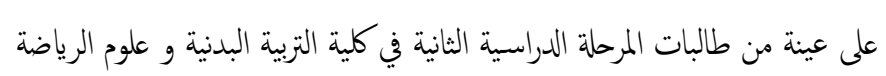
للبنات/ جامعة بغداد للعام الدراسي 2016-2017 ،و كانت الادوات المستخدمة لجمع البيانات اختبارات (السيادة المخية، التفكير ما وراء المعرفة ، اختبارات محارية لمهارتي الضرب الساحق و حائط الصد )، و استخدمة الباحثة الوسائل الاحصائية المناسبة و استنتجت ان استعمال استراتيجية الخزائط الدلالية للطالبات ذوات

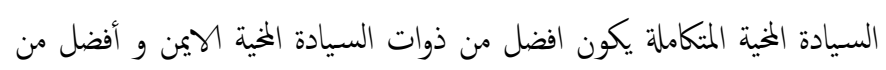
ذوات السيادة الخخية الايسر في تحسين التفكير ما وراء المعرفة .

2.2.2 دراسة: حزة واخرين (2013) اثر الخزائط الدلالية في التحصيل و الاستبقاء لدى تلميذات الصف الخامس الابتدائي في مادة العلوم العامة 


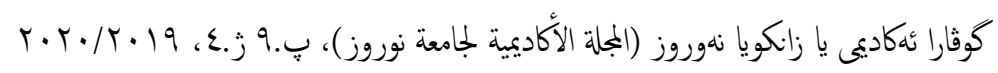

أساتذة جامعيين من المتخصصين في طرائق التدريس والتياس والتقو.يم إذ قامو بإبداء ارائهم وملاحظاتهم حول مناسبة فقرات الاختبار بنسبة (100\%). اما ثبات الاختبار فتم التحقق من ثبات اختبار تركيز الانتباه بطريقة اعادة الاختبار اذ تم تطبيق الاختبار على (10) طلاب من مجتمع البحث و خارج عينة البحث مرتين وتتخلل بنهها مدة اسبوعين و تم ايجاد معامل الارتباط وكانت (0.88).

\subsection{3 وصف اختبار التحصيل المعرفي}

يتكون اختبار التحصيل المعرفي من (50) فقرة من الفقرات موضوعية (25) فقرة

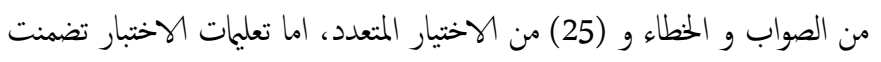
تعليات الإجابة وضعت التعليات الخاصة بالاختبار و كيفية الاجابة عنه و اشتمل مثال محلول يوضح كيفية الاجابة، اما تعليمات التصحيح وضح مفاتيح الإجابة لجميع فقرات الاختبار إذ يعطى درجة واحدة للإجابة صحيحة و صفر درجة للإجابة الخاطئة او الفقرات المتروكة بدون إجابة و الفقرات المجاب عليها بأكثر من إجابة. 2.5.3 وصف اختبار تركيز الاتثباه أن المقياس عبارة عن ورقة تحتوي على (31) سطر من الأرقام العربية الموزعة على شكل بمحوعات تتكون كل بمحوعة من (3-5) أرقام ويتتوي كل سطر على (10) بموعات مجموع أرقامها (40) رقاً وبموجبه يحتوي الاختبار على (1240) رقاً وقد وضعت أرقام هذا الاختبار تحت ترتيب وتسلسل مقنن كما روعي في وضعها أن

تكون غير منتظمة في توزيعها وغير متساوية لتفادي احتمالات الحفظ 0 يتم شرح الاختبار للطلبة عن طريق ملاحظتهم لورقة المقياس وكما يأتي :أنظر إلى الورقة التي امامك بجيث تلاحظ الأرقام والتزاكيب الموجودة بصورة جيدة وحاول أن تبحث عن الأرقام المطلوب منك شطبها وذلك بوضع خط عليها بالقلم ، وعلى الطالب أن يراعي الدقة والسرعة قدر المستطاع لان مـدة الاختبار ( دقيقة واحدة ) فتط بجيث يقوم بشطب كل بمموعة تنهي بالرقٍ ( 97 ) وتبدأ بالأسطر الواحد بعد ألآخر من اليسار المى اليمين يبدأ الاختبار بكلمة ( أستعد ) وعند سهاعها يأخذ ( الطالب ) ورقة الاختبار الموضوعة أمامه بصورة مقلوبة تعطى بعدها كلمة ( ابدأ ) فيقوم الطالب بشطب الأرقام المطلوبة وعند انتهاء وقت الاختبار وهو ( دقيقة واحدة ) وتعطى كلمة ( قق ) ثم يقوم الطالب بوضع خط تحت أخر بمموعة وصل إيها ويؤدي الطالب هذا الاختبار مرتين الأول منها يكون في مكان هادي ، أما في الثاني فيؤدي بوجود مثير ضوئ ومثير صوتي ، وأنه في الوقت الذي تعطى

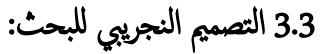

استخدم الباحث التصميم التجريبي الذي يطلق عليه (تصميم المجموعات العشوائية الاختيار المتكفئة ذات الاختيار القبلي و البعدي)، كما مبين في الشكل (1)

\begin{tabular}{|c|c|c|c|}
\hline الاختبار البعدي & المتغير التجريبي & الاختبار & \\
\hline مقياس الانتباه و اختبار & الخرائط الدلالية & الانتباه & التجموعة \\
\hline مقياس الانتباه و اختبار & الاسلوب المتبع & الانتباه & الضابطة \\
\hline
\end{tabular}

من أجل الوصول إلى تكفؤ بموعتي البحث قام الباحث بإجراء اختبارات التكافؤ بين بموعتي البحث بهدف ضبط المتغيرات ذات العلاقة بالبحث والتي من الممكن ان تؤثر في النتأُج التجريبية ومن هذه المتغيرات (العمر الزمني بالاشهر، الذكاء، مقياس الانتباه)، تم الرجوع المى وحدة التسجيل في فاكولتي التزبية لحصر عمر الطلبة وقياسها بالاشهر، ثخ تم اختبار المصفوفات رافن والمطبق على نفس بيئة البحث في أكثر من بحث الذي صمم لقياس الذكاء. والجدول (2) ييين ذلك الجدول 2

بيين النكفؤ في العمر و الذكاءو الانتباه

\begin{tabular}{|c|c|c|c|c|c|c|}
\hline 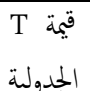 & قيمة المحتسبة & \multicolumn{2}{|c|}{ المجموعة الضابطة } & \multicolumn{2}{|c|}{ الجمموعة التجريبية } & \\
\hline \multirow{3}{*}{2.05} & 0.143 & 1.863 & 264.459 & 1.962 & 257.635 & العمر الزمني \\
\hline & 1.256 & 7.05 & 46.83 & 6.13 & 45.76 & الذكاء \\
\hline & 1.864 & 25.368 & 262.357 & 20.853 & 259.453 & الانتباه \\
\hline
\end{tabular}

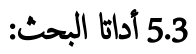

تم الاستعانة باختبار التحصيل المعرفي المعد من قبل (الجبوري، 2015)، كان هذا الاختبار قد طبق على طلاب السنة الدراسية الثانية في كلية التربية الرياضية جامعة سوران وهي عينة مشاهة لعينة البحث الحالي، وتم الاستعانة باختبار (بوردن - انفيموف) لقياس تركيز الانتباه (البيك، 1987، ص524)، ولغرض التحقق من صدق الاختبارين تم عرض الاختبارين (الملحق 1) على بموعة من 


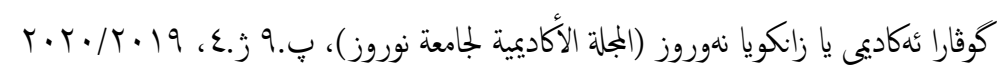

تعليميتين التي شملة عملية تفيذ البرنامج التعليمي إذ قام الباحث بإعداد استبيان حول خطة الدرس الملحق (1) والتي وزعت على السادة الختصين في مجال الطرائق الندريس والتي تضمنت أنموذجاً لخطة تدريس وفق استراتيجية الخرائط الدلالية 7.3 تطبيق التجربية الرئسية للبحث: بعد اجراء التكفؤ بين بموعتي التجريبة والضابطة وبعد القيام بالاختبار القبلي وتوفير مستلزمات الضرورية لتطبيق تجربة البحث الرئيسية تمت عملية تطبيق التجربة وبواقع وحدتين تعلميتين في الاسبوع وكان عدد الوحدات التعليمة التي تم تنفيذها (10) وحدات و بواقع وحدتين في الاسبوع وكان زمن المستغرق لكل وحدة (90) دقيقة وحسب ماهو مقرر للمنهج في قسم التربية الرياضية و بدأت التجربة بتاريخ 2019/2/3 2019 / / 2016 لغنمرت لغاية

8.3 الوسائل الإحصائية

(الاختبار النائي للعينات المتزابطة، الاختبار النائي للعينات المستقلة، معامل

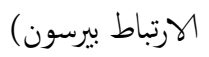
4. ترض النتاجُ والمناقشة 1.4 عرض نتاجُج الفرضية الاولى ومناقشتها:

$$
\text { الجدول } 4
$$

يبين الأوساط الحسابية والاخرافات المعيارية وقيم (ت) الحتسبة وقيمة (ت) المجدولة لدى طلاب الجموعة التجريبية والضابطة للاختبارين القبلي والبعدي على اختبار تركيز الانتباه

\begin{tabular}{|c|c|c|c|c|c|c|}
\hline \multirow{2}{*}{ قالجدمة (ت) } & \multirow{2}{*}{ قلمتمة (ت) } & \multicolumn{2}{|c|}{ الاختبار البعدي } & \multicolumn{2}{|c|}{ الاختبار القبلي } & \multirow{2}{*}{ الاختبار } \\
\hline & & $\varepsilon$ & س س & $\varepsilon$ & س & \\
\hline \multirow{3}{*}{2.16} & 4.346 & 17.364 & 191.621 & 20.853 & 259.453 & المجموعة \\
\hline & & & & & & السجريبي \\
\hline & 3.265 & 19.346 & 203.764 & 25.368 & 262.357 & الضابطة \\
\hline
\end{tabular}

معنوي عند نسبة خطأ (0.05) ودرجة حرية (14)

$$
\text { الجدول } 5
$$

يبين الأوساط الحسابية والأخرافات المعيارية و قيم (ت) المختسبة و قيمة (ت) الجمدولة لدى

\begin{tabular}{|c|c|c|c|c|c|c|}
\hline \multirow{2}{*}{ قيمة (ت) } & \multirow{2}{*}{ قلميمة (ت) } & \multicolumn{2}{|c|}{ المجموعة الضابطة } & \multicolumn{2}{|c|}{ المجموعة التجريبية } & \multirow{2}{*}{ المختبار } \\
\hline & & $\varepsilon$ & س & $\varepsilon$ & س & \\
\hline 2.05 & 3.896 & 19.346 & 203.764 & 17.364 & 191.621 & اختركيز \\
\hline
\end{tabular}
طلاب المجموعة التجريية و الضابطة للاختبار البعدي على اختبار تركيز الانتباه فيه كلمة ( ابدأ ) يقوم الباحث بتشغيل بجاز كهربائي مشتت للانتباه فيه مصباح ضوئي يعطي ومضة كل ( 5 ) ثوان علماً أن الجهاز موضوع على منضدة بجيث يكون المصباح في مجال رؤية الطالب وكذلك يوجد في الجهاز مشتت صوتي يعطي (60) دقة في الدقيقة الواحدة.

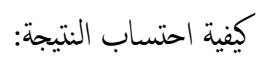
من أجل التوصل إلى درجة تركيز الانتباه على الباحث بالإجراءات الآتية: استخراج الحجم العام للجزء المنظور من الاختبار أي (كمية الأرقام التي تم رؤيتها) من البداية وحتى كلمة قف ويرمز لها بالرمز (ع) . استخراج عدد الأرقام (97) المفروض شطها في الجزء المنظور ويرمز لها بالرمز (ط) والتي يتم استخرابها بواسطة مفناح الاختبار. العدد العام للأخطاء (عدد الأرقام الساقطة من الشطب + عدد الأرقام التي شطبت خطأ) ويرمز لها بالرمز (خ). معدل صحة العمل بالمعادلة ويرمز لها بالرمز (ق) حيث: أ. ب. بعدها يتم استخراج مدة الانتباه ويرمز لها بالمعادلة الآتية:

$$
\text { ج }
$$
بعد احتساب المدة بالاختبارين نخصل على: صافي إنتاجية العمل عند قياس مدة الانتباه في الحالة الهادئة وبدون مشتت ويرمز لها بالرمز (ها 1). صافي إنتاجية العمل عند قياس مدة الانتبـاه مع المثير الصوتي ويرمز لها

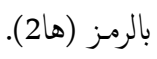
أن تركيز الانتباه يزمز له بالرمز (ت) وهو يستخرج من المعادلة الآتية:

$$
(1 \text { (1) }
$$

وكلما انخضضت القيمة المستخرجة دل هذا على ارتفاع التركيز عند الخمتبر.

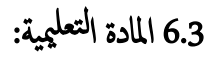

بغرض تطبيق تجربة البحث قام الباحث بإعداد المتطلبات التدريسية للمادة التعليمية والتي تشمل الخطط التدريسية اليومية للاسابيع المخسة ولكل اسبوع وحدتين 


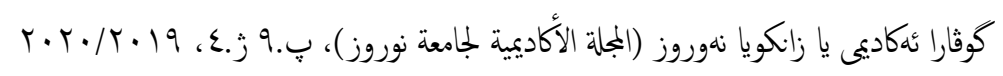

خلال قيام الطالب بالتخطيط والبحث عن المعرفة بنفسه ولا يجلس ينترها من المدرس ثم يتابع عملية تعلمه وجعله مسؤولا عن ما يتعلمه لذا تجبر استراتيجة الخرائط الدلالية الطالب ان يكون اكثر انتباه و يقضة اثناء المحاضرة لان انقطاعه عن المحاضرة يؤدي الي تشتت افكاره و مفاهيه وعدم امكانه من المشاركة في بناء الخزيطة،اذ يشير (الحارثي , 2007) "هندف استراتيجية الخرائط الدلالية إلى أن يخطط الطالب ويراقب ويسيطر ويقوم تعلمه الخاص وبالتالي فهي تعمل على تحسين الانتباه للطلبة لعمليات التعلم الختلفة وتسمح لهم بتحمل المسؤولية والتحكم في العمليات المعرفية المرتبطة بالتعلم" . (الحارثي

$(52,2007$,

من خلال استخدام استراتيجية الخرائط الدلالية يقوم المدرس بالتككيد على بزيادة انتباه الطلبة في كل مرحلة من مراحل بناء الخريطة الدلالية بصورة مباشرة و غير مبانشرة لاداء واجباتهم و المهام الموكل عليهم اثناء المحاضرة لاستحضار المفاهيم المرتبطة بالخريطة المراد بنائها وماهي المفاهيم المتوفر لديهم وماهي المفاهيم التي تنقصهم لبناء المعرفة بالصورة النكملية لم و ماهي مصادر المعرفة التي يكن ان تلبي حاجتهم لحل مشكلاتهم التعلمية والوصول الى تحقيق الاهداف التعلمية وهذا ما اكده (ابو جادو و نوفل ، 2007) "من مراحل استراتيجيات ما وراء المعرفة توجيه الطالب بطريقة شعورية و مقصودة بأدائه من همات او ما يقوم به الاخرون من انماط سلوكية و اداء مختلف ويكن ان يكون الانتباه في اتجاهين الاول عند وجود نموذج معين يقوم الطالب بملاحظته و الثاني عندما يقوم الطالب بالانتباه لمحتوى تجربة شخصية يمر بها

بنفسه". (ابو جادو ونوفل، 2007، 353) 3.4 عرض نتاجُ الفرضية الثانية ومناقثتها 1.3.4 عرض نثائج الفرضية الثانية

$$
\text { الجدول } 6
$$

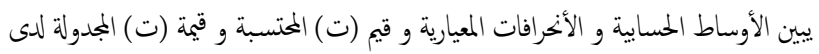

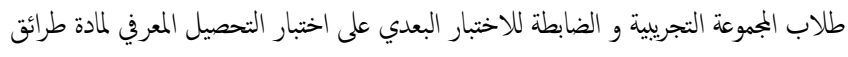

\begin{tabular}{|c|c|c|c|c|c|c|}
\hline \multicolumn{7}{|c|}{ الندريس } \\
\hline قيمة (ت) & قيمة (ت) & ضابطة & المجموعة & جريبية & | المجموعة | & المجاميع \\
\hline الجدولية & المحتسبة & $\varepsilon$ & س س & $\varepsilon$ & س س & الاختبار \\
\hline 2.05 & 3.062 & 13.231 & 32.167 & 8.656 & 38.356 & التحصيل \\
\hline
\end{tabular}

معنوي عند نسبة خطأ (0.05) ودرجة حرية (28)

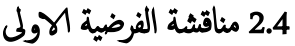

أظهرت نتائج الاختبار التائي بين المجموعتين التجريبة والضابطة فروقاً ذات دلالة إحصائية في تركيز الانتباه ولصاح الجمموعة التجريبية، في حين أظهرت نتائج الاختبار الثائي بين الاختبار القبلي والبعدي في تركيز الانتباه للمجموعة التجريبية فروقاً ذات دلالة إحصائية ولصاح الاختبار البعدي، وهذا يعطي دلالة واضحة إلى فاعلية تأثير

$$
\begin{aligned}
& \text { استراتيجية الخرائط الدلالية في تنمية تركيز الانتباه. } \\
& \text { ويعزو الباحث اسباب هذه النتائُ الى }
\end{aligned}
$$

- - في استراتيجية الخزائط الدلالية التي تعتبر احد استراتيجيات ما وراء المعرفة يكون الطالب فيها قادراً على وصف ما يدور في ذهنه من افكلر و مفاهيم من خلال مراحل بناء الخزيطة الدلالية و يستطع ايظاً وصف الخطوات التي يتبعها في بناء الخريطة ويقرر ماذا ومتى يستعمل افكاره أثناء التعلم ويتعرف على المعوقات التي توابحه في حل مشكلات النعلم كما يتمكن من تحديد نواحي النقص في المعلومات التي يمتلكها ، ويضع خطة منظمة لتحليل المواقت التعلمية ويعرف من اين يبدأ لحل تلك المشكلات التي لديه لتحقق الاهداف التعلمية مما يزيد من الشعور بمسؤولية النعلم لذا يجعل الطالب اكثر تركيزاً

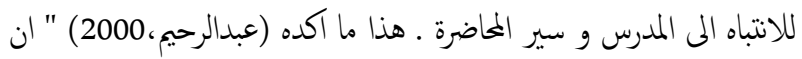
الاهتام بتنمية قدرة الطلبة على التحكم بوعي في عملية التفكير وإطلاق طاقات الإبداع تتطلب الخروج من ثقافة المعلومات إلى ثقافة بناء المعلومات ومعالجتها وتحويلها إلى معرفة ، ومن ثم الانتقال من مرحلة المعرفة إلى مرحلة ما وراء المعرفة ، وذلك عن طريق تنمية مارات ما وراء المعرفة لدى الطلبة ، حتى تنمو لليهم القدرة على التجديد والابنكار وتنمو قدرتهم على الاتتباه. ( عبد الرحيم ،

( 20 ، 2000 ويشير ايظاً (محمو،2006) الى "ان التدريس بالحرائط الدلاليةيعمل على ايجاد عامل الانتباه و الادراك علاقات و ارتباطات ذات معنى بين المفاهيم التي لها دور في نقل المعرفة بعد معالجتها" ـ (محمود، 20016، 303) - - ان استراتيجية الخزائط الدلالية تعمل خلق جو تعليم تعاوني بين الطالب و المدرس و يعطي للطالب دوراً للمشاركة الفعلية في بناء الخريطة الدلالية من 


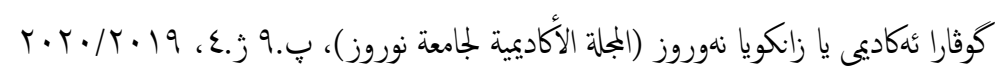

حسب نوع الخريطة ثم يصنف هذه المفاهيم ويربطها مع بعضها ويعيد ترتيها و تنظيمها في مجالات متشابه في شكل خريطة دلالية للموضوع ويضيف اليها مفاهيم اخرى جديدة لدى الطالب يربط المعلومات الجديدة بالمعلومات السابقة عند الطالب مما يؤدي أكتساب مفاهيم اخرى جديدة ، وهذا ما اشار اليه "الخزائط الدلالية استراتيجية تدريس تعمل لإعادة تنظيم (Ricahad, 1993) النص في إطار تصنيفي مشاهد يربط الكلمات الجديدة مع المعلومات المخزونة في عقل القارئ مما يساعده على وضع المفاهيم و المعلومات التفيلية تحت مiاهيم و أفكار عامة على شكل علاقات متبادلة (Ricahad, 1993, 449) وهذا ما اشار اليه ايظاً (الفرماوي، 2009)" الخريطة الدلالية تطبيق لنظرية الخططط العقلي في التدريس عندما يعد المدرس و الطالب بناء النص و تنظمه في شكل خريطة دلالية لموضوع المحاضرة تتوقف و تتشابه مع شبكات المخطط العقلي للطالب وهي بذلك تتوقف مع افكار أوزوبل التي تعتني بتتابع المحتوى التعليمي من العام الى الخاص وكذلك المنظات المتقدمة التي تساعد الطالب

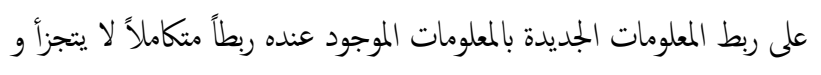
بالنتيجة يصبح التعلم ذا معنى ويبقى اثره مدة طويلة . (الفرماوي، 2009، 19) كذلك دور الطالب الفعال و النشط في بناء الخزيطة الدلالية من خلال المناقشات الصفية بين الطالب و المدرس فهو المستفيد و المتحكم في بناء الخريطة إذ انه يمارس التفكير و النقد وتساعده الى زيادة السرعة في استرجاع المعلومات إذ يقدم المفاهيم الرئيسية و الفرعية و يصنفها الى بموعات ويحث على استخراج المفاهيم لاضافتها المى الخريطة الدلالية وهذا ما اشار اليه (المسعودي،2013) "ان استراتيجية الخزايط الدلالية مغتوحة لتنظيم المعلومات بيانياً عن طريق عرض العلاقات بين المفاهيم و الكلمات العامة و تفاصيلها الجزئية باعتبارها لا ترتبط بشكل معين أو ثابت بل متغير و مرن كلما كثرت مناقشات المدرس و تنوعت في استثارة الخبرات السابقة للطلاب و معلومات النصوص ازدادت المعلومات التي تحتوبها الخريطة الدلالية". (المسعودي،98، 3013 ) (198)

5. 5 الاستناجات و التوصيات 1.5
معنوي عند نسبة خطأ (0.05) ودرجة حرية (28)

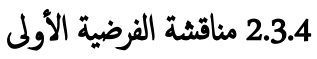

نتائج الاختبار التائي لاختبار التحصيل المعرفي لمادة طرائق التدريس أظهرت تفوق المجموعة التجريبية والتي تدرس وفق استراتيجية الخرائط الدلالية على المجموعة الضابطة التي تدرس وفق الأسلوب المستخدم ويعزو الباحث هذه النتائج الى :- استراتيجية الخرائط الدلالية تسمح للطالب امكانية تحويل النص التعليمي المقروئ الى خريطة معلومانية مترابطة تقسم الهفاهيم الى اساسية و فرعية التي لها انواع مختلف حسب نوع و طبيعة المادة التعليمية لنكشف بشكل جيد النية المفاهيمة للنص التي تحلل النص الى مجموعة من المفاهيم الرئيسية وما يندرج تحتها من مفاهيم فرعية ويتحول النص بها إلى مجموعة من المفاهيم و المعارف التي ترتبط مع بعضها البعض وهذا ما اشار اليه (المسعودي،2013) " ان الخرائط الدلالية استراتيجية تدريس تعمل على اعادة تنظيم النص المقروء بشكل رسوم بيانية و تخطيطية تقوم على وضع التفاصيل الجزئية في علاقات مع الافكلر الرئيسية و المفاهيم الاساسية في ارتباط مع المفاهيم الفرعية ومن خلال المناقشة المتبادلة بين المدرس و الطالب لمعلومات النص المقروء و معلومات الطلاب السابقة. ( المسعودي، 2013، 99) - - مان بناء الخزائط الدلالية من قبل المدرس و الطالب تساعد على تنشيط فكر الطلبة و تحفز معلوماته للمادة المعرفية حول موضوع المحاضرة لغرض المشاركة و التقديم وتساعده في تنظيم مفاهيم جديدة وإيجاد النكلمل بين المفاهيم الجديدة والقديمة من خلال مشاركته في بناء الخزيطة الدلالية، وهذا ما اشار اليه (حمزة واخرين،2013) " الخريطة الدلالية وسيلة تساعد الطلبة على العمل الجماعي بتنمية روح التعاون والاحتزام المتبادل بين المدرس وطالبه (أدارة الاتصال بين المدرس والطالب) وتهيئ في الوقت نفس الطالب للفهم والمحكاة وتقويم المعلومات التي يقرؤونها فان تمكن الطلبة من الإلمام بهذه المعلومات فانها تساعده على تفهم الموضوع المراد فهمه و إدراكه ( ممزة واخرين، 2013،

- - من خلال اجراءات بناء الخريطة الدلالية يوثير المدرس المفاهيم السابقة الخززونة لدى الطالب اثناء مرحلة العصف الذهني ثم يضعها في الخريطة 


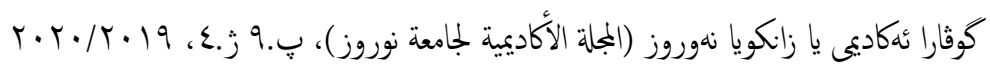

4. الحارثي , سارة مصلح (2007) :الوعي بهارات ما وراء المعرفة لدى طالبات كلية التربية

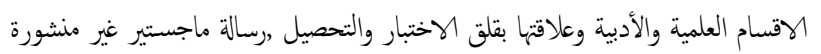

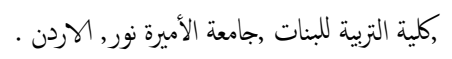

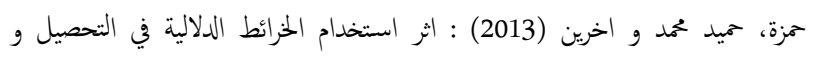

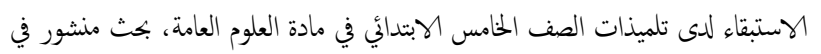

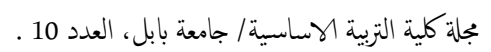

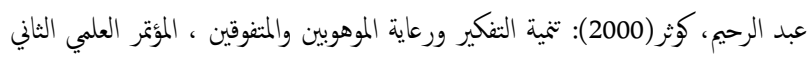

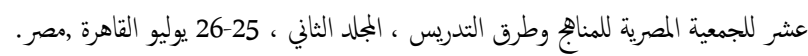

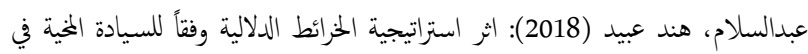

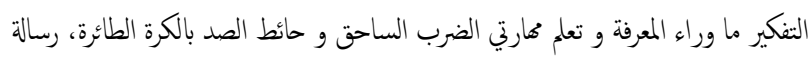

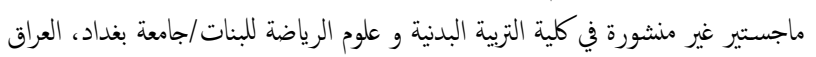

8. الفرماوي، حمدي علي (2009): الاساليب المعرفية ( بين النظرية و التطبيق)، دار صفاء

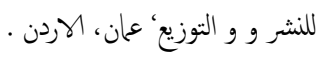

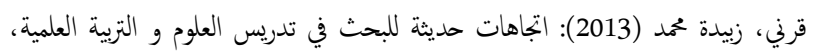

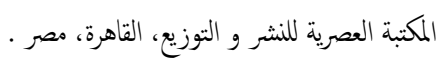

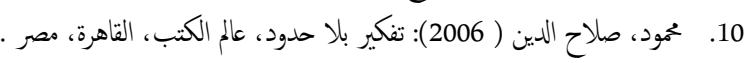

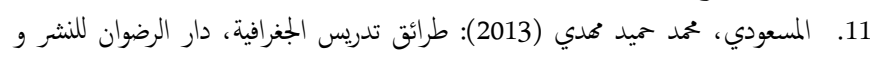
التوزيع،عان، الاردن.

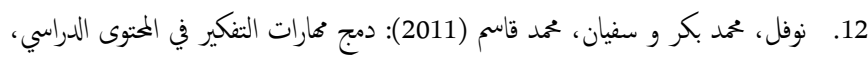

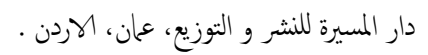

13. Richard, C Sinatra (1993): Through Semantic mapplig, The Reading improvimg, Reading comprehension of disabled reading teacher.
تفوقت المجموعة التجريبية في اختبار التحصيل المعرفي و مقياس تزكيز الانتباه

$$
\text { على المجموعة الضابطة. }
$$

ساهت استراتيجة الخرائط الدلالية بتفوق المجموعة التجريية في اختبار

$$
\text { التحصيل المعرفي. }
$$

ساهمت استراتيجية الخزائط الدلالية والاسلوب المتبع في رفع مستوى التزكيز للانتباه للمجموعة النجريبية والظابطة ولكن كان ثاثيرالحزائط الدلالية أكبر من الاسلوب المتبع.

2.5

إمكانية استخدام استراتيجية الخزائط الدلالية في تعليم العلوم الرياضية من قبل المدرسين كأحد الاستراتيجيات الفعالة من استراتيجيات ما وراء المعرفة والتي يؤدي استخدامها الى تحقيق أهداف التربية الرياضية. إمكانية إعادة تنظيم محتوى مناهج مادة طرائق التدريس باستخدام الخرائط الدلالية وتحديد العلاقات بين المفاهيم بصورة واضحة. تضمين أدلة للمدرسين بمعلومات لتوضيح كيفية استخدام استراتيجية الخرائط الدلالية في تدريس مادة طرائق التدريس في علوم التربية الرياضية بصورة عامة ومادة طرائق التدريس بصورة خاصة. إجراء دراسات أخرى لاستراتيجيات الخزائط الدلالية في تدريس وعلى دروس علمية اخرى في مجال التربية الرياضية.

إعداد دراسة لبناء برنامج تدريبي لتطوير مارات الندريس وفق استراتيجيات ما وراء المعرفة لدى مدرسي التربية الرياضية في مختلف المراحل التعليمية. 6 - - المصادر 1. ابو جادو، صالح محمد و نوفل، محمد بكر (2007): تعليم الثفكير النظرية و التطبيق، دار

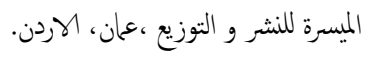
2.

3. الجبوري، بسام فوزي (2015): تطبيق آليات إديكسل لضان جودة التعليم في التحصيل

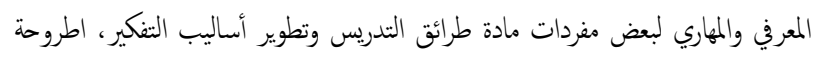

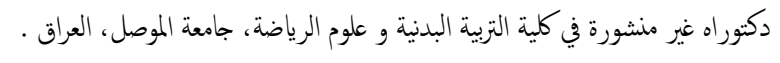




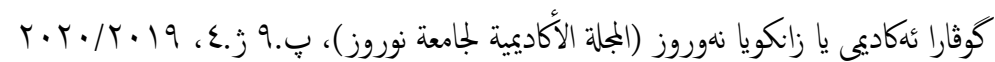




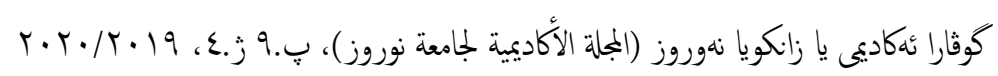

(3) الملحق)

استمارة استبيان حول الخطة الثدريسية وفق استراتيجية الخرائط الدلالية و صلاحية اختبار تركيز الاتباه و اختبار التحصيل المعرفي

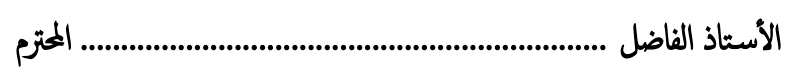

تحية طيبة

يروم الباحث إجراء البحث الموسوم (اثر استخدام استراتيجية الخرائط الدلالية على تنمية الاثتباه و التحصيل المعرفي لبعض مفردات مادة طرائق الثدريس). ونظراً

لما تتمتعون به من خبرة و دراية علمية في مجال الطرائق التدريس و القياس و التقويم، أرجو التفضل ببيان مدى صلاحية الخطة التدريسية المرفقة لندريس طلبة قسم التربية

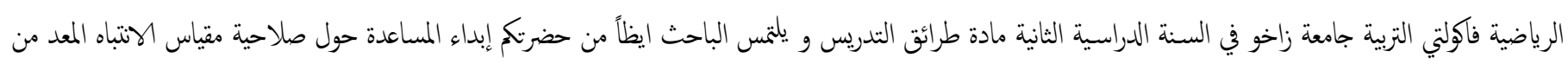
قبل ( البيك، 1987)، و لكون الباحث يحتاج المى اختبار معرفي لقياس التحصيل المعرفي لذا فقد استعان الباحث باختبار المعرفي المعد من قبل (الجبوري، 2014) ويتكون من (50) فقرة ، علاً بان الاختبار طبق على نفس العينة في قسم التربية الرياضية كلية التربية جامعة سوران لنا يلتمس الباحث من حضرتكم إبداء المساعدة في تقنين الفقرات اختبار التحصيل المعرفي لمادة طرائق الثدريس و تعديل اية فقرة ترونها مناسبة.

شاكرين تعاونكم معنا خدمة للبحث العلمي

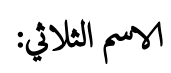

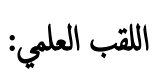

الاختصاص:

مكان العمل: - م

التاريخ :

التوقيع:

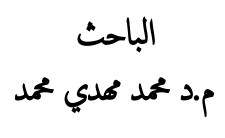


كوفارا أنهاديى يا زانكويا نهوروز (الجلة الأكاديمة لجامعة نوروز)، ت.9 ز.ع، 19

$$
\text { نموذج لوحدة تعلميمة وفق استراتيجية الخرائط الدلالية }
$$

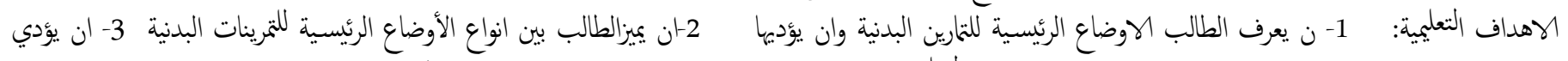

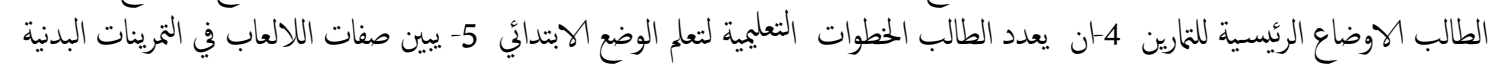

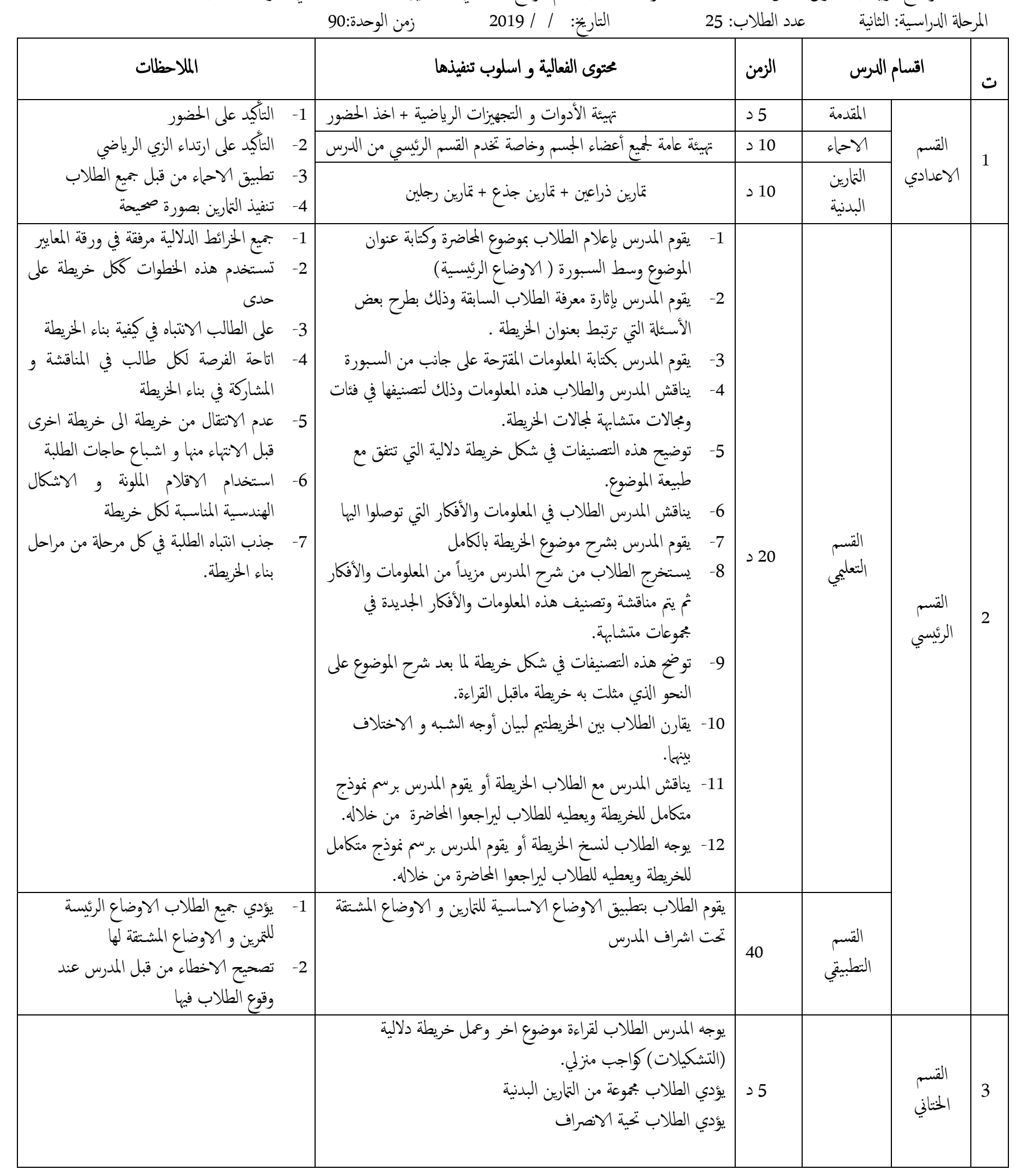




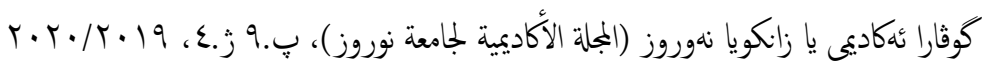

(1) الخزيطة رخ
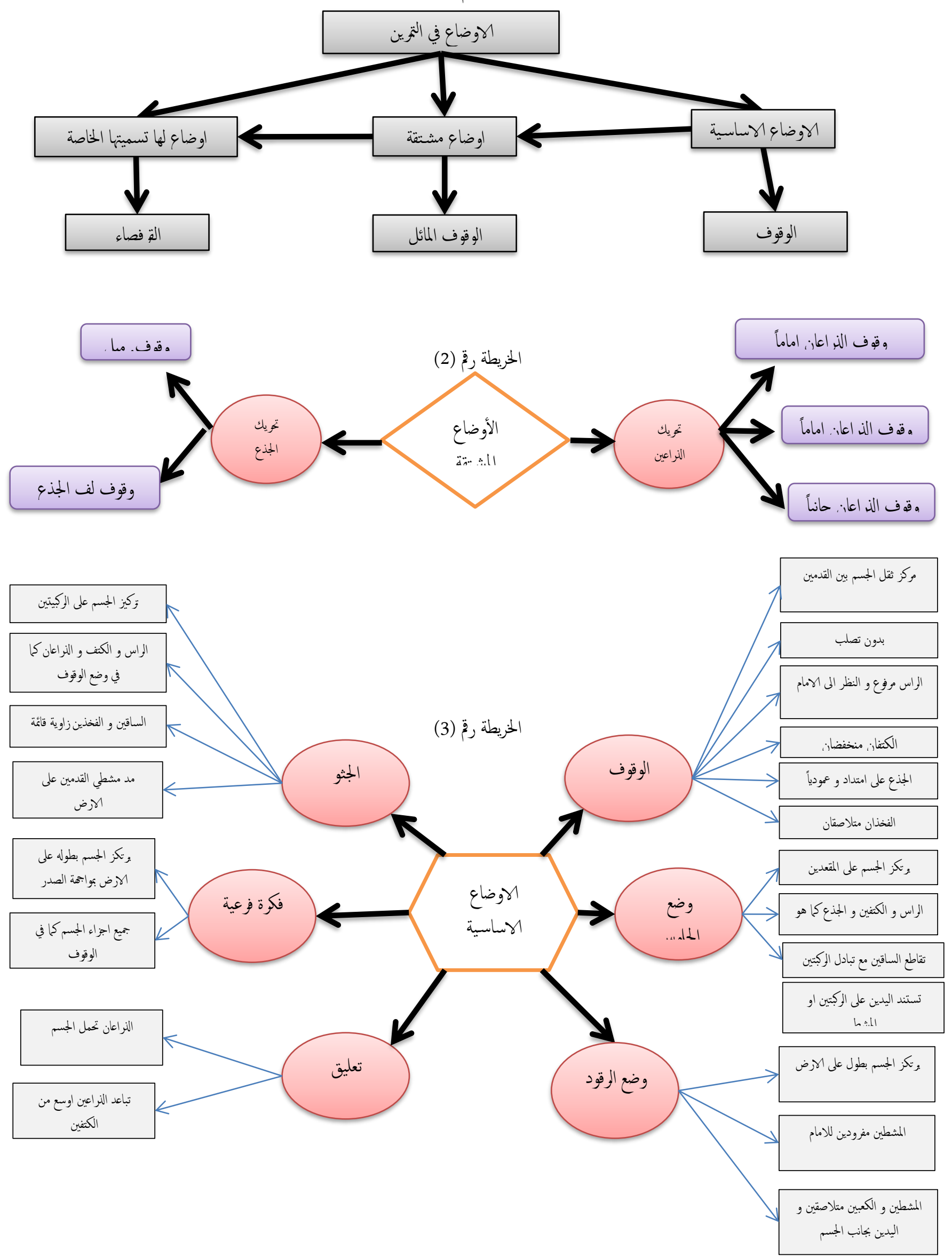
اختبار التحصيل المعرفي لمادة طرائت التدريس

\section{1 ضع علامة ل ل امام الاجابة الصحيحة وعلامة X امام الاجابة الخاطية}

1- الخطة الطويلة المدى (الخطة السنوية) هي خطة بعيدة المدى يروم المدرس فهيا تحقيق اهداف تعليمية.

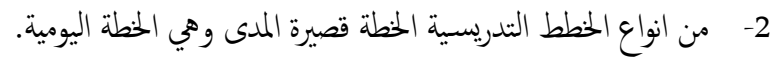

3- الخطة المتوسطة المدى هي التي يخطط لهاع على مدى (شئل الخهر ) واحد.

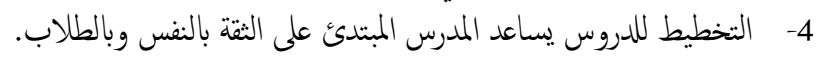

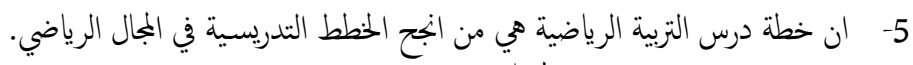

6- الجزء الرئيسي يتضمن القسم النعليمي والقسم التطبيقي.

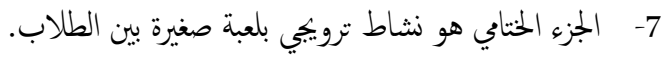

8-

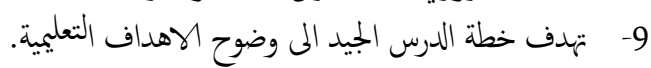

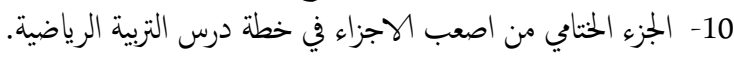

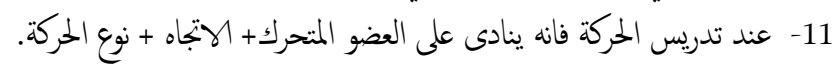

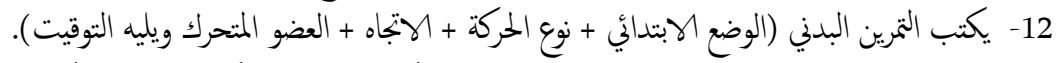

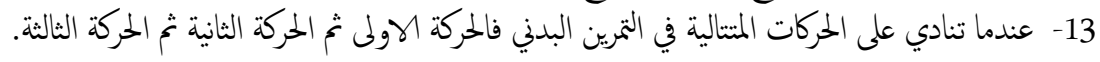

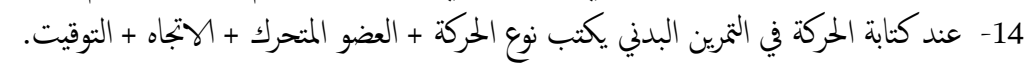

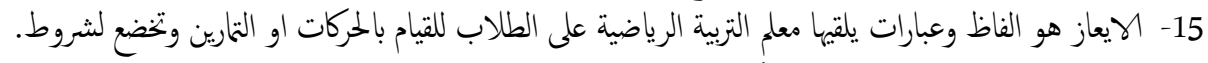

16- الاوضاع الاساسية للنمارين البدنية تتكون من سبعة اوضاع.

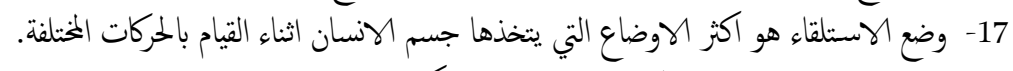

18- يراعي في وضع الوقوف تقاطع الرجلين مع تباعد الركبتين.

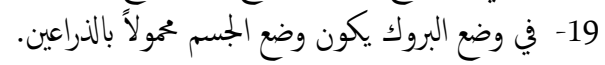

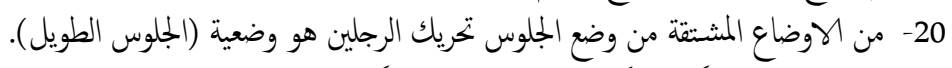

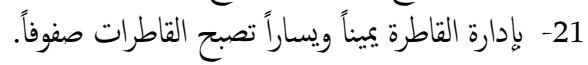

22- الوضع المنشر هو من يسىى بالتشكيل الحر.

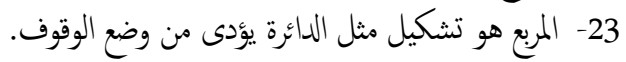

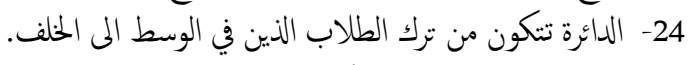

25- النسق هو (الوقوف - فتحاً) على يمين القدرة.

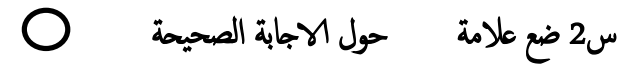

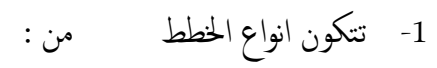

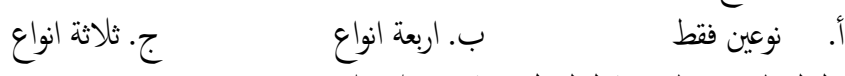

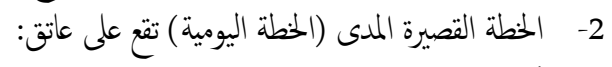

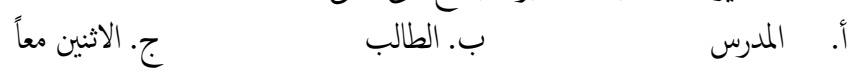

$$
\begin{aligned}
& \text { 3- ميجب ان تمتوي خطة درس التربية الرياضية على: }
\end{aligned}
$$

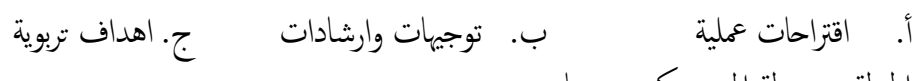

$$
\begin{aligned}
& \text { 4- الخطة متوسطة المدى تكون مدتها: }
\end{aligned}
$$

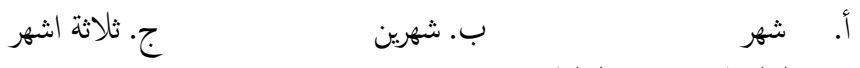

$$
\begin{aligned}
& \text { 5- أ. تعد الخطة اليومية من الخطط: }
\end{aligned}
$$

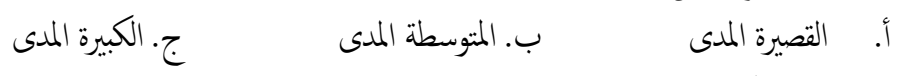

$$
\begin{aligned}
& \text { 6- من ضمن خطة درس التربية الرياضية: }
\end{aligned}
$$

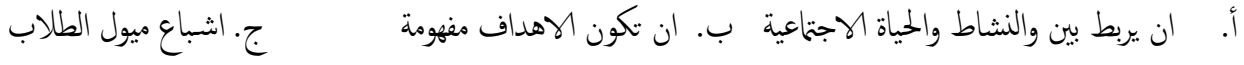




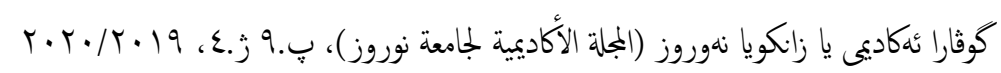

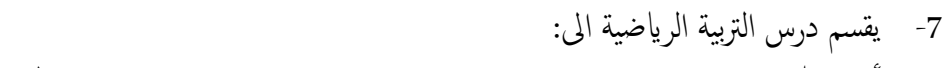

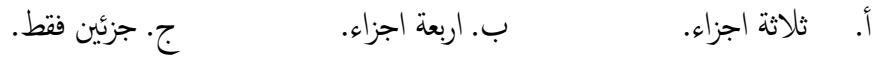

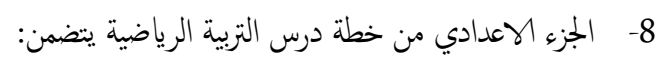

$$
\begin{aligned}
& \text { أ. المقدمة + الاحماء + تمارين بدنية. } \\
& \text { ب. بأ الجزء التطبيقي + الجزء التعليمي. }
\end{aligned}
$$

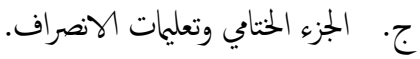

$$
\begin{aligned}
& \text { 9- الجزء الرئيسي يجب ان: }
\end{aligned}
$$

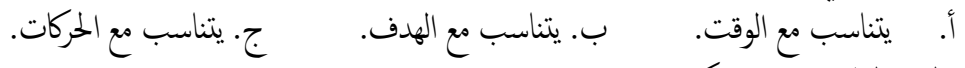

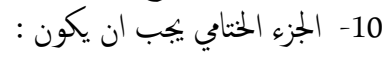

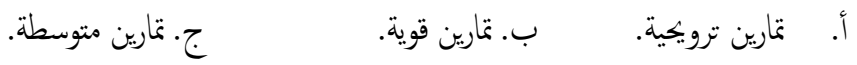

$$
\begin{aligned}
& \text { 11- القسم الاخباري من الايعاز عبارة عن: }
\end{aligned}
$$

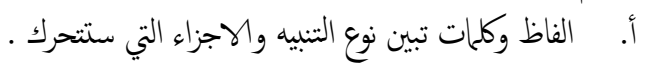

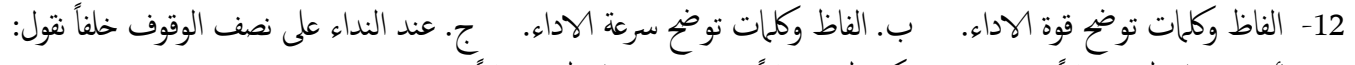

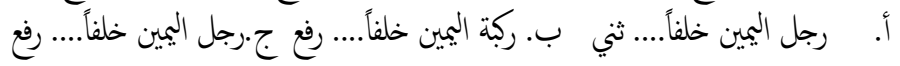

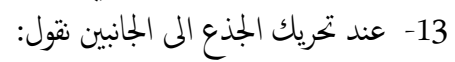

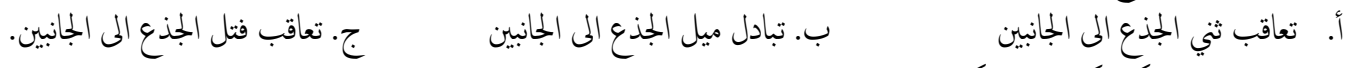

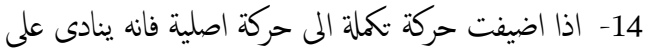

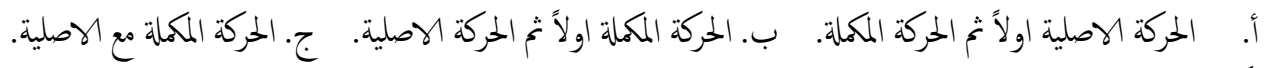

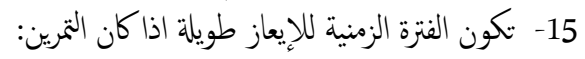

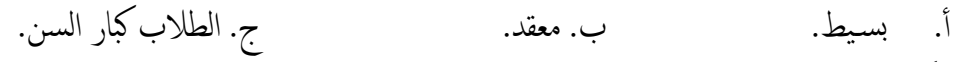

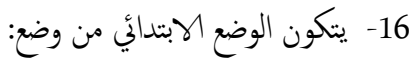

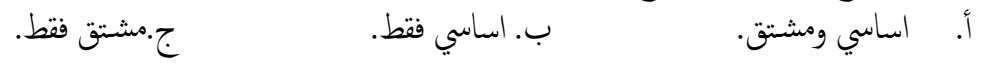

$$
\begin{aligned}
& \text { 17- تقسم التمارين البدنية بصورة عامة الى تمارين: }
\end{aligned}
$$

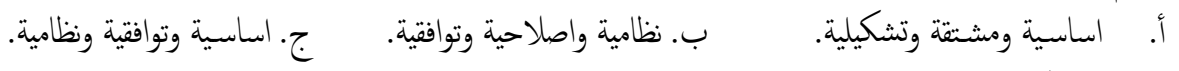

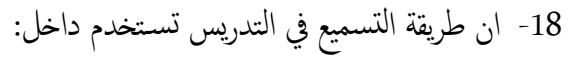

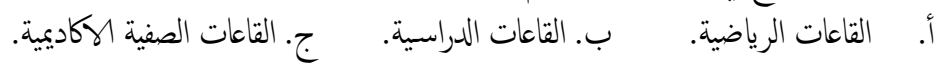

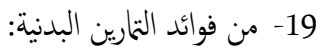

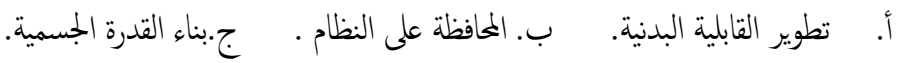

$$
\begin{aligned}
& \text { 20- من الصفات التي تحققها الالعاب في التمارين البدنية: }
\end{aligned}
$$

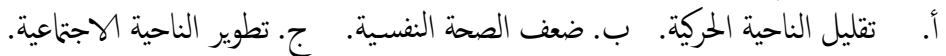

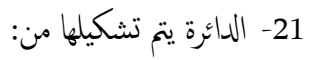

$$
\begin{aligned}
& \text { أ. من تشكيل صف. }
\end{aligned}
$$

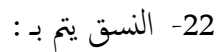

$$
\begin{aligned}
& \text { أ. أ. هرولة الطلاب بكل نشاط. ب. ب. مشي الطلاب بكل نشاط ج. الركض بأقصى سرعة. } \\
& \text { 23- تتكون الصفوف بـ: } \\
& \text { أ. أد ادارة القاطرة يميناً او يساراً. ب. بالوضع المنشر (التشكيل الحر). ج. بالهرولة. } \\
& \text { 24- المربع يقف الطلاب في: }
\end{aligned}
$$

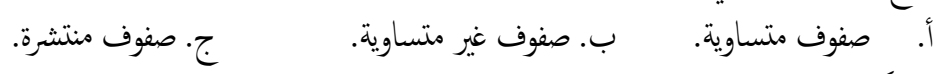

$$
\begin{aligned}
& \text { 25- التشكيل الحر هو وقوف الطلاب في مجموعات: } \\
& \text { ج· متساوية. }
\end{aligned}
$$

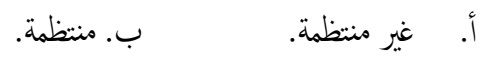




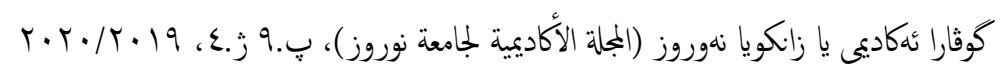

استمارة اختبار ( بوردون - انفيموف) لتزكيز الانتباه

\begin{tabular}{|c|c|c|c|c|c|c|c|c|c|}
\hline 2497 & 6942 & 583 & 64279 & 2749 & 2496 & 385 & 62479 & 6492 & 2947 \\
\hline 92474 & 538 & 2496 & 2947 & 583 & 6492 & 2946 & 2974 & 2497 & 67429 \\
\hline 385 & 2497 & 6492 & 67249 & 2469 & 2947 & 385 & 2947 & 2647 & 29476 \\
\hline 2492 & 2496 & 583 & 2497 & 67429 & 2947 & 2492 & 2946 & 2497 & 2497 \\
\hline 6497 & 67249 & 2497 & 2749 & 2947 & 64279 & 6492 & 385 & 2496 & 385 \\
\hline 62479 & 2947 & 6492 & 583 & 2497 & 92476 & 385 & 2496 & 583 & 67429 \\
\hline 583 & 2496 & 67249 & 2492 & 2946 & 583 & 64279 & 385 & 2492 & 92476 \\
\hline 6492 & 2947 & 6942 & 764229 & 583 & 2497 & 358 & 2974 & 67249 & 2946 \\
\hline 385 & 2496 & 583 & 64279 & 385 & 67249 & 92476 & 62479 & 385 & 2492 \\
\hline 67429 & 583 & 6492 & 583 & 62479 & 2947 & 385 & 62479 & 64279 & 375 \\
\hline 6942 & 385 & 64279 & 2947 & 6492 & 583 & 2497 & 4962 & 2947 & 62479 \\
\hline 68429 & 2947 & 538 & 92476 & 2496 & 2946 & 2947 & 583 & 2497 & 6429 \\
\hline 385 & 2749 & 2947 & 2492 & 67249 & 583 & 2496 & 2492 & 92476 & 2947 \\
\hline 2946 & 2629 & 385 & 2496 & 2497 & 6492 & 2497 & 67429 & 2947 & 2496 \\
\hline 7496 & 67249 & 2497 & 2947 & 2749 & 64279 & 385 & 6492 & 385 & 2497 \\
\hline 92476 & 2496 & 6492 & 583 & 2947 & 67429 & 385 & 2496 & 62479 & 583 \\
\hline 538 & 67249 & 2496 & 6492 & 583 & 2497 & 64279 & 2947 & 385 & 92476 \\
\hline 67429 & 6492 & 2947 & 2924 & 2946 & 67249 & 2974 & 385 & 2497 & 583 \\
\hline 2416 & 385 & 62479 & 62479 & 385 & 2497 & 583 & 92476 & 67249 & 385 \\
\hline 2947 & 62479 & 6492 & 358 & 67429 & 385 & 583 & 62479 & 583 & 64239 \\
\hline 6492 & 2947 & 62479 & 385 & 2496 & 2749 & 64279 & 583 & 6429 & 2497 \\
\hline 67429 & 2497 & 2974 & 2946 & 6492 & 258 & 2947 & 2496 & 538 & 92476 \\
\hline 385 & 3947 & 2496 & 67249 & 6492 & 2497 & 385 & 92476 & 2947 & 2749 \\
\hline 2496 & 2946 & 2497 & 2492 & 2947 & 67429 & 2497 & 583 & 2496 & 6492 \\
\hline 358 & 2496 & 385 & 6492 & 64279 & 2947 & 2749 & 2496 & 67249 & 2497 \\
\hline 67429 & 583 & 2496 & 385 & 92467 & 2497 & 583 & 6492 & 2947 & 62479 \\
\hline 29476 & 3497 & 358 & 62479 & 538 & 2947 & 6492 & 67349 & 2496 & 583 \\
\hline 2946 & 67249 & 2974 & 358 & 2497 & 583 & 67429 & 6942 & 2947 & 6492 \\
\hline 2497 & 358 & 62479 & 92476 & 67249 & 385 & 64279 & 583 & 2469 & 385 \\
\hline 583 & 64279 & 62479 & 258 & 2947 & 62479 & 583 & 6492 & 358 & 67429 \\
\hline 26476 & 2947 & 2496 & 2497 & 583 & 6492 & 2947 & 64279 & 358 & 6942 \\
\hline
\end{tabular}

